\title{
Desmatamento no Estado de Mato Grosso: Avaliação de Convergência e Interação Espacial (2000-2008)
}

\section{Deforestation in the Mato Grosso State: Convergence Assessment and Spatial Interaction (2000-2008)}

\author{
Rudolph Fabiano A. P. Teixeira* \\ Luciana Togeiro de Almeida** \\ Mario Augusto Bertella***
}

\begin{abstract}
Resumo: Este trabalho faz uma análise de convergência espacial para o processo de desmatamento em 139 municípios do estado de Mato Grosso durante o período de 2000 a 2008. Primeiramente, realiza-se uma análise exploratória de dados espaciais (Aede), que detecta a presença de autocorrelação espacial entre as taxas de desmatamento dos municípios da referida região. Dessa forma, pode-se considerar que o desmatamento não segue um processo aleatório no estado de Mato Grosso. Após isso, são estimados alguns modelos de $\beta$ convergência, indicando que o modelo de erro espacial é o que fornece melhores resultados. Contudo, mesmo o coeficiente $\beta$ sendo estatisticamente significativo para todos os períodos, apresenta sinal positivo, sugerindo que não ocorre convergência, mas sim incremento das disparidades regionais no processo de desmatamento.
\end{abstract}

Palavras-chave: Desmatamento. Econometria especial. $\beta$ convergência.

Abstract: This paper analyzes the spatialconvergence for the process of deforestation among 139 cities in the Mato Grosso State during the period 2000-2008. First, itcarried out an Exploratory Spatial Data Analysis (ESDA), which detected the presence ofspatial association between the rates of deforestation in municipalities of Mato Grosso State. Thus, we can considerthat deforestation does not follow a random process in thisregion. After that, it was estimated some models of $\beta$ convergence, indicating that the spatial error model is the best one. However, in spite of the coefficient $\beta$ being statistically significant in all periods, it has a positive

\footnotetext{
* Economista da Eletrobras e mestre em Economia pela Universidade Estadual Paulista Júlio de Mesquita (Unesp). E-mail: rudolphgp@hotmail.com

** Doutora em Economia pela Universidade Estadual de Campinas (Unicamp). Professora do Programa de Mestrado em Economia da Faculdade de Ciências e Letras da Universidade Estadual Paulista Júlio de Mesquita (FCLAR/Unesp). E-mail: itogeiro@gmail.com

*** Doutor em Economia pela Universidade Estadual de Campinas (Unicamp). Professor do Programa de Mestrado em Economia da FCLAR/Unesp. E-mail: mabertella@yahoo.com.br
} 
signal, suggesting that there is not a convergence, but an increase in the regional disparities in the process of deforestation.

Keywords: Deforestation. Spatial econometrics. $\beta$ convergence.

JEL Classification: R12; Q51.

\section{Introdução}

O estado de Mato Grosso é o campeão do desmatamento acumulado, com uma proporção de aproximadamente 36\% do total desmatado na Amazônia brasileira. Estimativas mostram que entre 1988 e 2008 foram desmatados 135 mil km² somente nesse estado, ou seja, uma área superior à soma dos territórios de Portugal (92 mil km²) e Holanda (41,5 mil km²), o que configura uma situação tida como alarmante (PPCDMT, 2009).

Em decorrência, estudos como o de Ferreira et al. (2008) trabalharam com a construção de cenários extremos, em que, mantidas as taxas de desmatamento do período 2003-2004, o estado de Mato Grosso contaria, em 2020, com menos de $23 \%$ da cobertura florestal original, enquanto que, em 2033, essa mesma parcela seria reduzida para cerca de $10 \%$.

No entanto, é importante frisar que o processo de desmatamento é complexo, e as origens apontadas pela literatura geral sobre o tema parecem se refletir plenamente no estado mato-grossense. A sustentação econômica do estado está fortemente atrelada à agropecuária das grandes propriedades. Nas últimas três décadas, o estado apresentou crescimento extraordinário nesse setor, mormente pela expansão da área cultivada, da área destinada à pecuária, da produção global e da produtividade. Esse desempenho só foi possível graças a uma sensível transformação da base técnico-produtiva, antes alicerçada em sistemas tradicionais, que foi alterada para sistemas de produção amparada em tecnologia (PPCDMT, 2009).

A literatura destaca o incremento da atividade pecuária (MARGULIS, 2003), a sojicultura (FEARNSIDE, 1999) e o corte de árvores (FEARNSIDE, 2003) como os principais vilões do processo de desmatamento no estado mato-grossense. Entre 1990 e 2008, o rebanho bovino em Mato Grosso sofreu um incremento de 9 para cerca de 26 milhões de cabeças, mantendo um ritmo de crescimento médio de aproximadamente 5,7\% ao ano. Paralelamente, a área plantada de soja no estado cresceu de 1,5 para 5,5 milhões de hectares no mesmo período, um incremento médio de 7,1\% ao ano. Já a extração de madeira em tora apresentou crescimen- 
to mais modesto, elevando-se de 16,8 mil de metros cúbicos, em 1990, para 20,2 mil metros cúbicos, em 2008, um aumento médio de 0,97\% ao ano ${ }^{1}$ (IBGE, 2009).

Micol, Andrade e Börner (2008) enfatizam que, além da conversão de florestas e cerrados em áreas voltadas ao agronegócio, nota-se também a conversão de áreas de pastagens em campos agrícolas no centro-norte do estado, bem como um deslocamento da pecuária para novas fronteiras no extremo norte e noroeste, contribuindo para o incremento do desmatamento em novas regiões.

Geist e Lambin (2001) fizeram um levantamento de 152 estudos de caso acerca das forças que atuam positivamente sobre o desmatamento, classificando-as em três diferentes categorias: a) causas agregadas primárias (diretas) e relacionadas: expansão da agricultura, extração da madeira e expansão da infraestrutura; b) forças direcionais subjacentes: incluem elementos de natureza demográfica, econômicos, institucionais, culturais e político-sociais; c) fatores heterogêneos que não guardam necessariamente relação entre si: por exemplo, pré-disposição ambiental, forças biofísicas e eventos aleatórios de natureza social.

O desmatamento em Mato Grosso se enquadra dentro das três categorias citadas, entretanto, as causas agregadas primárias e relacionadas predominam para a maioria dos pesquisadores sobre o tema (PPCDMT, 2009). Enfatiza-se que a atividade pecuária, a plantação da soja, a extração madeireira, ou todos esses fatores somados e mais alguns, como, por exemplo, a malha rodoviária e, mais recentemente, as grandes plantações de cana-de-açúcar, sejam os grandes responsáveis pelo desmatamento da referida região. ${ }^{2}$

O objetivo central deste trabalho é verificar a hipótese da convergência absoluta (ou $\beta$ convergência) do desmatamento entre os municípios do estado de Mato Grosso e suprir uma lacuna na literatura, tendo em vista a necessidade de se estudar a parte descendente da Curva de Kuznets Ambiental, de forma específica para Mato Grosso, dada a enorme importância ambiental dessa região. Como objetivos secundários, pretende-se investigar a existência ou não de autocorrelação espacial para o desmatamento entre os municípios de Mato Grosso, além de apontar quais as localidades que mais sofrem com a degradação florestal.

Para tal, além desta introdução, o artigo está dividido em mais cinco seções: a segunda seção faz uma breve revisão da literatura, a terceira trata do processo de convergência e dos conceitos básicos de econometria espacial, a quarta refere-se à metodologia e à base de dados, a quinta discute os resultados alcançados, e, por fim, a sexta traz as considerações finais.

\footnotetext{
1 É importante sublinhar que o Sistema IBGE de Recuperação Automática (Sidra) fornece dados apenas sobre a extração legal de madeira. Dessa forma, o volume de madeira oficialmente extraída em Mato Grosso, entre 1990 e 2008, provavelmente está muito aquém do verdadeiro nível. Segundo Fearnside (2003), em 1998, a Secretaria de Assuntos Estratégicos (SAE) calculou que $80 \%$ do volume de toras cortadas nos estados da Amazônia eram ilegais.

2 Para maiores detalhes sobre o processo de desmatamento em Mato Grosso, ver Teixeira (2010).
} 


\section{Breve Revisão da Literatura}

Por volta dos anos de 1970, existia uma crença generalizada de que o crescimento econômico de uma nação seria o grande responsável pelos problemas ambientais, ou seja, era consenso que existia uma relação positiva entre crescimento econômico e a degradação do meio ambiente (FONSECA; RIBEIRO, 2005). No entanto, a partir da década de 1990, alguns economistas passaram a argumentar que tal visão era extremamente pessimista, na medida em que desconsiderava as inovações tecnológicas, a melhoria da educação, o progresso econômico e a evolução das instituições no desenvolvimento de uma nação, o que poderia minorar os problemas ambientais (STERN, 1998).

O trabalho de Grossman e Krueger (1991) foi um dos primeiros a buscar, por meio de modelos econométricos, estabelecer uma possível relação entre degradação ambiental e crescimento econômico. Os autores se utilizaram de uma amostra cross-country de três tipos de poluentes (dióxido de enxofre - $\mathrm{SO}_{2}$, fumaça e partículas suspensas), localizados em áreas urbanas de 42 países, juntamente com o PIB per capita (e seu termo ao quadrado) apurado nos mesmos. Considerando o dióxido de enxofre e a fumaça, encontrou-se uma relação na forma de "U" invertido com a renda per capita. Isto é, em baixos níveis de renda, a degradação do meio ambiente aumentaria com o crescimento do PIB per capita até certo limite (ponto de máximo) e, a partir daí, com a expansão persistente do produto, os níveis de degradação passariam a declinar. Por sua vez, para o montante de partículas suspensas, a relação com a renda mostrou-se monotonicamente decrescente. A relação encontrada para os dois primeiros tipos de poluentes foi batizada de Curva de Kuznets Ambiental (CKA), tendo em vista a similaridade entre essa curva e aquela encontrada para o nível de renda e sua distribuição por Kuznets (1955).

Deve-se frisar que grande parcela dos estudos econômicos sobre temas atrelados à destruição do meio ambiente teve como objetivo estimar a hipótese da CKA, inclusive a de que a ocorrência do processo de convergência para um dado indicador de degradação ambiental entre distintas localidades estaria ligada à fase descendente da CKA, isto é, com o passar do tempo, regiões com elevada degradação ambiental alcançariam patamares de desenvolvimento econômico próximo ao de regióes desenvolvidas, com baixos índices de destruição do meio ambiente (ARRAES; DINIZ; DINIZ, 2006). Sendo assim, esta revisão da literatura irá contemplar alguns importantes trabalhos sobre as hipóteses da CKA e da convergência, relacionados aos indicadores de degradação ambiental.

Shafik e Bandyopadhyay (1992) utilizaram dez indicadores de qualidade ambiental, a saber, ausência de água tratada, ausência de saneamento básico, partículas suspensas, níveis de $\mathrm{SO}_{2}$, mudanças na área florestal, taxa anual de desmatamento, oxigênio dissolvido nos rios, coliformes fecais nos rios, lixo municipal per 
capita e emissões de gás carbônico per capita, para testar a hipótese da CKA em 149 países no período de 1960 a 1990.

Foram testados três modelos de dados em painel, nos quais os autores regrediram os indicadores ambientais contra a renda per capita, uma variável de tendência temporal para refletir as evoluções da tecnologia e um termo de efeitos fixos para as características específicas de cada localidade.

Considerando todos os indicadores abordados, surgiram diferentes resultados. Para as variáveis ausência de água tratada, ausência de saneamento básico, oxigênio dissolvido nos rios e coliformes fecais nos rios, os autores obtiveram uma relação negativa com o nível de renda. As medidas de desmatamento não revelaram relação com o produto per capita, ao passo que dois indicadores de poluição do ar ( $\mathrm{SO}_{2}$ e partículas suspensas) confirmaram a hipótese da CKA. Por sua vez, as emissões de carbono per capita e o lixo municipal per capita revelaram uma forte relação positiva com o crescimento do produto.

Stern (2000) foi um dos primeiros autores a estimar uma CKA considerando os aspectos espaciais da base de dados. Ele utilizou uma amostra de dados em painel com dependência espacial para 16 países da Europa Ocidental, durante o período 1960-1990. Como variável dependente, adotaram-se as emissões de $\mathrm{SO}_{2}$. Por sua vez, as variáveis explicativas utilizadas compreenderam a renda per capita, seu termo ao quadrado, além de uma variável de tendência de tempo. Os resultados indicaram a existência de uma CKA.

Maddison (2006), utilizando uma amostra de 135 países para os anos de 1990 e 1995, tentou verificar a hipótese de uma CKA global buscando assumir a dependência espacial da base de dados. Utilizando como variáveis dependentes emissões de $\mathrm{SO}_{2}$, monóxido de carbono (CO), óxidos de nitrogênio $\left(\mathrm{NO}_{x}\right)$ e uma mistura de componentes orgânicos, não foi encontrada a forma de " $U$ " invertido para nenhuma das equações apresentadas.

No Brasil, o trabalho de Carvalho e Almeida (2008) adotou uma amostra cross-section de 187 países para o ano de 2004, assumindo um contexto de dependência espacial. Como variável dependente, foi utilizada a emissão de dióxido de carbono $\left(\mathrm{CO}_{2}\right)$ em toneladas métricas per capita. A renda per capita, seu termo ao quadrado, o consumo de energia per capita, as exportações per capita e uma dummy para captar os países signatários do Protocolo de Kyoto foram tomadas como variáveis explicativas. O resultado encontrado foi uma CKA na forma de "U" invertido.

Fonseca e Ribeiro (2005) e Lucena (2005) foram os pioneiros a verificar a hipótese da CKA para o Brasil. Os dois primeiros, utilizando-se de dados em painel referentes ao percentual de áreas estaduais preservadas nas 27 unidades da federação, durante os anos de 1985, 1990, 1995 e 2000, encontraram resultados distintos, dependendo da forma funcional utilizada e do tamanho da amostra. $\mathrm{O}$ 
segundo estudo, por sua vez, considerando o Brasil como um todo, fez uso de uma amostra de série de tempo entre 1970 e 2003, utilizando emissões de $\mathrm{CO}_{2}$ como variável dependente. $\mathrm{O}$ autor não encontrou evidências de uma CKA.

Trabalhos mais recentes buscaram avaliar a hipótese da CKA para a Amazônia Legal brasileira. Gomes e Braga (2008) utilizaram dados sobre a taxa de desmatamento e a renda per capita nos estados da Amazônia Legal, durante o período de 1990 a 2004. Fazendo uso de uma modelagem de dados em painel para efeitos aleatórios, os autores adotaram a taxa de desmatamento, como a variável explicada e a renda per capita, seu termo ao quadrado, a densidade demográfica e o ano, como as explicativas. As estimações mostraram que, para a função quadrática da CKA, os resultados foram o inverso ao esperado, isto é, foi obtida uma CKA na forma de "U".

O trabalho de Santos et al. (2008) verificou a hipótese da CKA para 782 municípios da Amazônia Legal. Utilizando como variável dependente a área desmatada em hectares e, como variável explicativa, o PIB per capita e seu termo quadrático, foi testada empiricamente, através de dados em painel, a relação entre crescimento econômico e impacto ambiental durante os anos de 2000 a 2004. As evidências apontaram para a existência da CKA, porém com modelos pouco representativos.

Por fim, de maneira mais específica, Teixeira, Bertella e Almeida (2012) fizeram uso de dados sobre 139 municípios do estado de Mato Grosso para avaliar a hipótese da CKA durante o período de 2000 a 2008, controlando os efeitos espaciais. Como variável dependente, utilizou-se o logaritmo do desmatamento per capita, e, como variáveis independentes, o logaritmo da renda per capita, seu termo ao quadrado, o logaritmo da razão do rebanho bovino pela área de pastagem, o logaritmo da densidade demográfica e o logaritmo da extração de madeira per capita. Todos os modelos elaborados confirmaram a hipótese da CKA na forma de "U" invertido.

Com relação aos trabalhos de convergência (fase descendente da CKA), Arraes, Diniz e Diniz (2006) utilizaram distintas amostras de países e de indicadores de desenvolvimento sustentável para verificar a hipótese da convergência durante o período de 1980 a 2000, através da metodologia de dados em painel. De todos os indicadores adotados, apenas o déficit de analfabetismo apresentou convergência.

Reis e Guzmán (1992) elaboraram um modelo na tentativa de explicar o desmatamento da Amazônia no período de 1985 a 1995, construindo funções para a distribuição espacial (convergência) das principais atividades econômicas da região, isto é, o agregado das safras agrícolas, o estoque de gado, a quantidade de madeira em toras e a quantidade de estradas. Os resultados indicaram que todas essas atividades revelaram convergência.

Igliori (2008) buscou explicar o processo de desmatamento da Amazônia Legal de 257 áreas geográficas comparáveis durante o período 1970-1997. O autor 
elaborou modelos de convergência condicional utilizando-se da metodologia da econometria espacial com dados em painel. As variáveis dependentes foram a taxa de desmatamento e o produto de um determinado município. Por sua vez, foram utilizadas diferentes variáveis explicativas conforme cada modelo. Os resultados indicaram convergência para quase todos os modelos, com a maior parte apresentando resultados significativos.

O Quadro 1 sintetiza alguns dos principais trabalhos sobre a hipótese da CKA e o processo de convergência ambiental, tanto em nível internacional (diversos países), quanto em nível nacional (Brasil), regional (Amazônia) e local (estado de Mato Grosso). 


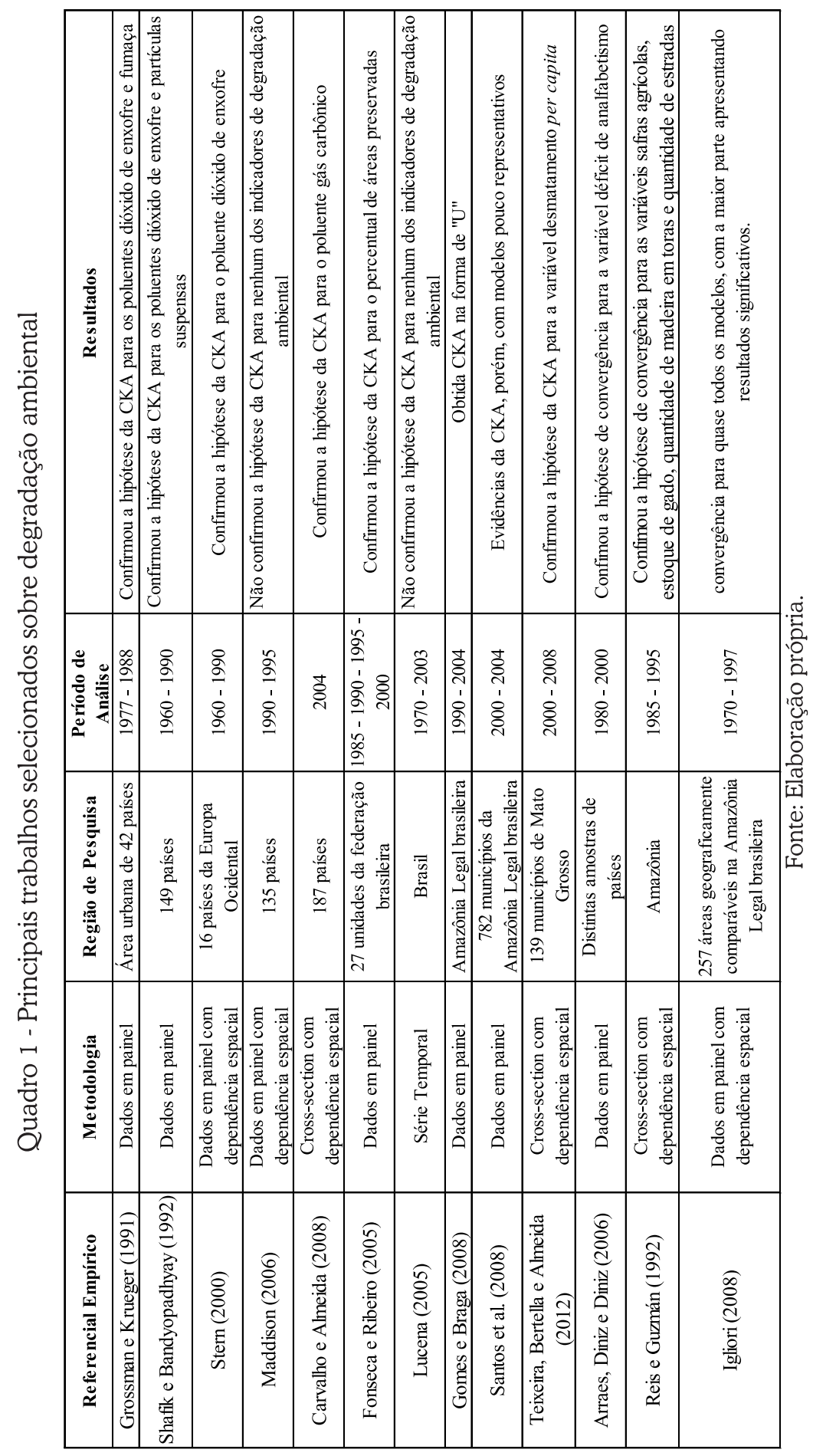




\section{Convergência e Econometria Espacial}

Independentemente dos potenciais fatores explicativos do desmatamento, um processo que pode estar ocorrendo entre os municípios do estado de Mato Grosso e que ainda não foi investigado é o processo de convergência do desmatamento. Nas palavras de Lopes (2004), "[...] a convergência é um processo em que uma mesma variável (por exemplo, renda per capita ou produtividade da terra) apresenta diferentes valores entre países, regiões ou estados, mas essa diferença se reduz ao longo do tempo, indicando que a desigualdade diminui".

O trabalho seminal de Baumol (1986) examinou a dinâmica da convergência da renda de 1870 a 1979 entre 16 países industrializados, de acordo com a seguinte expressão:

$$
\ln (Y / N)_{i, t}-\ln (Y / N)_{i, t-1}=\alpha+\beta \ln (Y / N)_{i, t-1}+\varepsilon_{i}
$$

em que $1 n(Y / N)$ é o logaritmo da renda per capita, $\varepsilon$ é o termo de erro, $i$ é o indexador para os diversos países e $t$ refere-se aos anos utilizados na análise.

Conforme Baumol (1986), se houver convergência absoluta, $\beta$ será negativo, ou seja, países com renda inicial maior teriam menores taxas de crescimento, ao passo que países dotados de renda inicial menor possuiriam maiores taxas de crescimento. No limite, a tendência é que tais rendas se igualem ao longo do tempo (BARRO; SALA-I-MARTIN, 1991).

É importante destacar a existência de trabalhos como o de Rey e Montoury (1999), que aplicou a análise da convergência da renda sob a ótica da econometria espacial para a economia norte-americana, e o de Dall'erba (2003), que estimou a convergência do trabalho para 48 regiões da Espanha entre 1980 e 1996, utilizando-se da mesma metodologia.

No Brasil, a tese de Lopes (2004) fez uso da econometria espacial para avaliar o processo de convergência da produtividade da terra para as 11 principais culturas brasileiras entre os estados produtores. O trabalho de Perobelli, Ferreira e Faria (2006) utilizou a mesma técnica para analisar a convergência da renda entre as microrregiões mineiras. Mais recentemente, Almeida, Perobelli e Ferreira (2008) investigaram o processo de $\beta$ convergência da produtividade agrícola no Brasil entre os diferentes estados, controlando os efeitos espaciais.

Brock e Taylor (2010) consideram que estudos de convergência também podem ser realizados com a utilização de indicadores de desenvolvimento sustentável. A ideia básica seria verificar se localidades pobres, com um nível elevado de degradação ambiental e social, estariam convergindo para níveis próximos aos de regiões desenvolvidas, ou seja, de reduzida exploração ambiental e social. Essa lógica também estaria atrelada ao processo de crescimento econômico. 
O objetivo deste trabalho é adaptar a ideia de Baumol (1986) para entender o comportamento do processo de desmatamento em Mato Grosso, um importante estado da região amazônica. Assim, ao se formalizar uma equação de convergência absoluta para o desmatamento no estado, buscar-se-á verificar se municípios com maiores taxas de desmatamento estão convergindo para níveis similares ao dos municípios com menor grau de desmatamento. Resumidamente, este trabalho pretende utilizar a análise de convergência para testar se as taxas de desmatamento entre os municípios mato-grossenses estão ficando mais homogêneas com o passar do tempo.

Um aspecto relevante do artigo é o seu período de análise (2000-2008). Esse período pode ser considerado um verdadeiro marco tanto no avanço das discussões sobre o desmatamento, quanto na gestão de recursos ambientais. Foi a partir desse período que o governo federal brasileiro e os estados passaram a dar maior importância à questão ambiental, através da inclusão da rubrica de despesa ambiental em seus respectivos orçamentos financeiros.

Nesse sentido, o estado de Mato Grosso apresentou uma configuração bastante instável em sua despesa com gestão ambiental no período 2000-2003, graças à inclusão desse item em seu passivo financeiro somente a partir de 2002. Isto é, nos anos de 2000 e 2001 essa rubrica não constava no balanço financeiro do estado. Já no período 2004-2008, as despesas com gestão ambiental se consolidaram e passaram a demonstrar uma tendência positiva.

A primeira estimativa do presente trabalho testa se no período de 2000 a 2008 existe convergência das taxas de desmatamento entre os municípios do estado de Mato Grosso. Essa análise é preponderante, pois engloba os dados mais recentes sobre o processo de desmatamento no estado. A segunda estimativa de convergência aplica-se ao subperíodo de 2000 a 2003 e pode ser justificada pelo início da inclusão do gasto ambiental no passivo estadual mato-grossense. Por sua vez, a terceira estimativa de convergência engloba o subperíodo de 2004 a 2008, no qual a despesa ambiental estadual passa a sofrer um processo de consolidação e apresenta uma tendência positiva de incremento ao longo do tempo. O Gráfico 1 mostra o desempenho da despesa ambiental no estado de Mato Grosso. 
Gráfico 1 - Despesa com gestão ambiental no estado de Mato Grosso

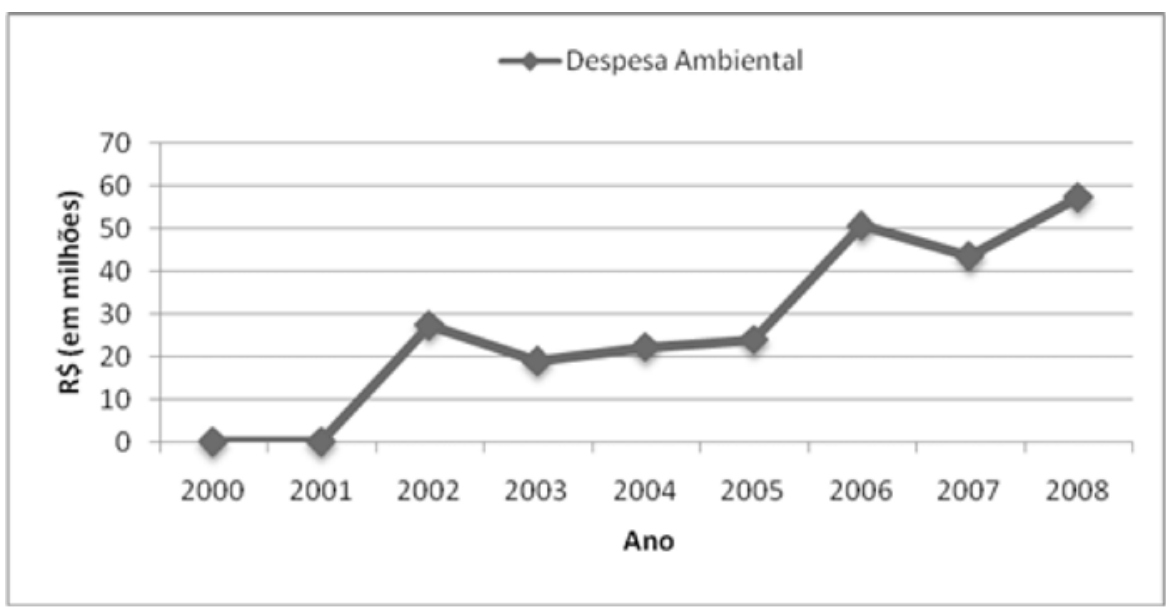

Fonte: Elaboração própria a partir de dados de Brasil (2009).

Durante o subperíodo 2000-2003, o gasto ambiental do estado de Mato Grosso mostrou-se instável. Nos dois primeiros anos de análise, 2000 e 2001, essa despesa foi nula, pois não constava no planejamento orçamentário dos estados brasileiros. A partir do ano de 2002, esse item passa a fazer parte da pauta das despesas estaduais, configurando um montante gasto de $\mathrm{R} \$ 27,3$ milhões em Mato Grosso. No ano de 2003, essa mesma despesa apresentou um valor de R\$18,9 milhões. Resumidamente, nesse período o aumento das preocupações ambientais no estado de Mato Grosso pode ser configurado como de relativa inconsistência, dado o caráter ainda bastante incipiente do planejamento estadual em meio ambiente.

Contudo, o subperíodo seguinte, de 2004 a 2008, mostra-se mais robusto, pois o gasto ambiental no estado evolui continuamente de 2004 a 2006, ou seja, de $R$ \$ 22,2 milhões para $R$ \$ 50,5 milhões, respectivamente. No ano de 2007, essa despesa sofre redução para $\mathrm{R} \$ 43,4$ milhões, mas em 2008 o volume do gasto com gestão ambiental volta a se recuperar, expandindo-se para $\mathrm{R} \$ 57,2$ milhões.

Dessa forma, o processo de desmatamento em Mato Grosso deve ser verificado não somente à luz do período de 2000 a 2008, mas também nos subperíodos de 2000 a 2003 e de 2004 a 2008. Essa medida mostra-se relevante, tendo em vista as divergências estruturais na despesa ambiental do estado. No mais, a quebra estrutural em modelos econômicos é recomendada por De Long (1988).

Vale observar também a importância da utilização da econometria espacial nos estudos de convergência. De acordo com Quah (1996), a maioria dos trabalhos sobre convergência utiliza dados regionais, enquanto grande parte trata as regiões como unidades isoladas, ou seja, não explicitando a interação em seu entorno. Nesse aspecto, um modelo de convergência, composto por dados organizados em unidades espaciais, deveria levar em consideração os efeitos espaciais 
que poderiam resultar da interação espacial entre os distintos agentes (REY; MONTOURY, 1999).

A diferença entre a econometria espacial e a econometria convencional concentra-se na preocupação de se incorporar na primeira o padrão da interação socioeconômica entre os agentes em um sistema, assim como as características da estrutura desse sistema no espaço. Essas interações e as características estruturais - que podem ser instáveis no espaço - geram efeitos espaciais em vários processos de várias naturezas, e não apenas de cunho econômico (ANSELIN, 1988; ANSELIN; SYABRI; SMIRNOV, 2003; ANSELIN; BERA, 1998).

De acordo com Odland (1988, p. 13), “[...] a interação espacial, que é o movimento de bens, pessoas ou informação através do espaço, significa que eventos ou circunstâncias num lugar podem afetar as condições em outros lugares se os lugares interagem entre si".

Nesse contexto, o conceito de dependência espacial torna-se condição sine qua non para se entender a interação espacial ou os vários processos que possuem efeitos espaciais. A dependência espacial pode ser compreendida, por sua vez, através do valor de uma variável de interesse numa dada região $i$, digamos $y_{i}$, que depende do valor dessa mesma variável nas regiões vizinhas j, ou seja, $y_{j}$ (PEROBELLI et al., 2007).

Existem três fontes primárias de dependência espacial que podem ser destacadas: a primeira relaciona-se à variedade de processos de interação espacial, como, por exemplo, o processo de difusão espacial (difusão tecnológica, por exemplo), a troca de mercadorias entre as regiões (comércio), o comportamento estratégico (interdependência dos agentes nas regiões) e a dispersão ou espraiamento (a fronteira agrícola, por exemplo); a segunda vinculada a erros nos dados espaciais, ocasionada pela falta ou baixa correspondência entre o escopo do fenômeno em estudo e o zoneamento das unidades espaciais (distritos, municípios, microrregióes, etc.); a terceira diz respeito a erros de especificação do modelo. Pode-se denominar a primeira fonte como sendo autêntica e as duas outras como espúrias (ANSELIN, 1988).

É fácil verificar que o processo de desmatamento é muito sensível aos efeitos espaciais. A queima de florestas, o desenvolvimento de culturas agrícolas, a pecuária e o comércio clandestino de madeira são alguns fatores que se desenvolvem heterogeneamente no espaço, independentemente do zoneamento legal de uma unidade geográfica.

Em suma, este trabalho apresenta uma análise de convergência absoluta para o processo de desmatamento entre os municípios mato-grossenses, controlando-se os efeitos espaciais. Na presença desses efeitos, os métodos econométricos tradicionais levam à inferência espúria, com danos para a formulação de políticas públicas. 


\section{Base de Dados e Metodologia}

Este trabalho fez uso dos softwares GeoDa (Geodata Analysis) e Spacestat 1.91, além da base de dados do Instituto Nacional de Pesquisas Espaciais (INPE, 2009), referente ao desmatamento do estado de Mato Grosso, consultada através do Programa de Cálculo do Desflorestamento na Amazônia (BRASIL, 2009a). Para a elaboração do artigo, foram compilados dados sobre o desmatamento em uma amostra de 139 municípios mato-grossenses, durante o período de 2000 a 2008, além dos subperíodos de 2000 a 2003 e de 2004 a 2008. A variável adotada é a taxa de desmatamento em um determinado município, isto é, a razão da área desmatada pela área total do mesmo.

A utilização de dados recentes é fundamental em trabalhos que busquem estimar o processo de convergência, mitigando problemas metodológicos. Além disso, também é uma boa ideia estimar equações de convergência para subperíodos da amostra, pois os resultados encontrados podem auxiliar a entender o desenvolvimento do processo de convergência como um todo (DE LONG, 1988).

Entretanto, ao se estudar a configuração do desmatamento recente em âmbito regional, é importante saber quais são as localidades que mais sofrem com esse processo. Segundo o estudo de Alencar et al. (2004), os principais focos do desmatamento em Mato Grosso localizam-se, concentrados, principalmente ao longo das rodovias Cuiabá-Santarém (BR-163) e (BR-158), nas regiões centro-norte e nordeste. Na rodovia Cuiabá-Santarém, o principal foco de desmatamento ocorre na região de Sinop, onde a expansão da cultura de grãos e da atividade pecuária está motivando a derrubada de florestas. Os municípios de Novo Mundo e Guarantã do Norte também apresentaram desmatamento intenso recente, mas com esse processo sendo explicado pelo estabelecimento de projetos de assentamento e de colonização na região.

Um aspecto importante a ser abordado refere-se a uma lista divulgada pelo governo federal contendo 43 municípios considerados críticos para o desmatamento da Amazônia Legal, dos quais 20 estão localizados no estado de Mato Grosso (Figura 1), ou seja, quase $50 \%$, o que explica a forte preocupação do governo e da sociedade com o desmatamento desse estado. 
Figura 1 - Localização espacial dos municípios considerados críticos no desmatamento do estado de Mato Grosso

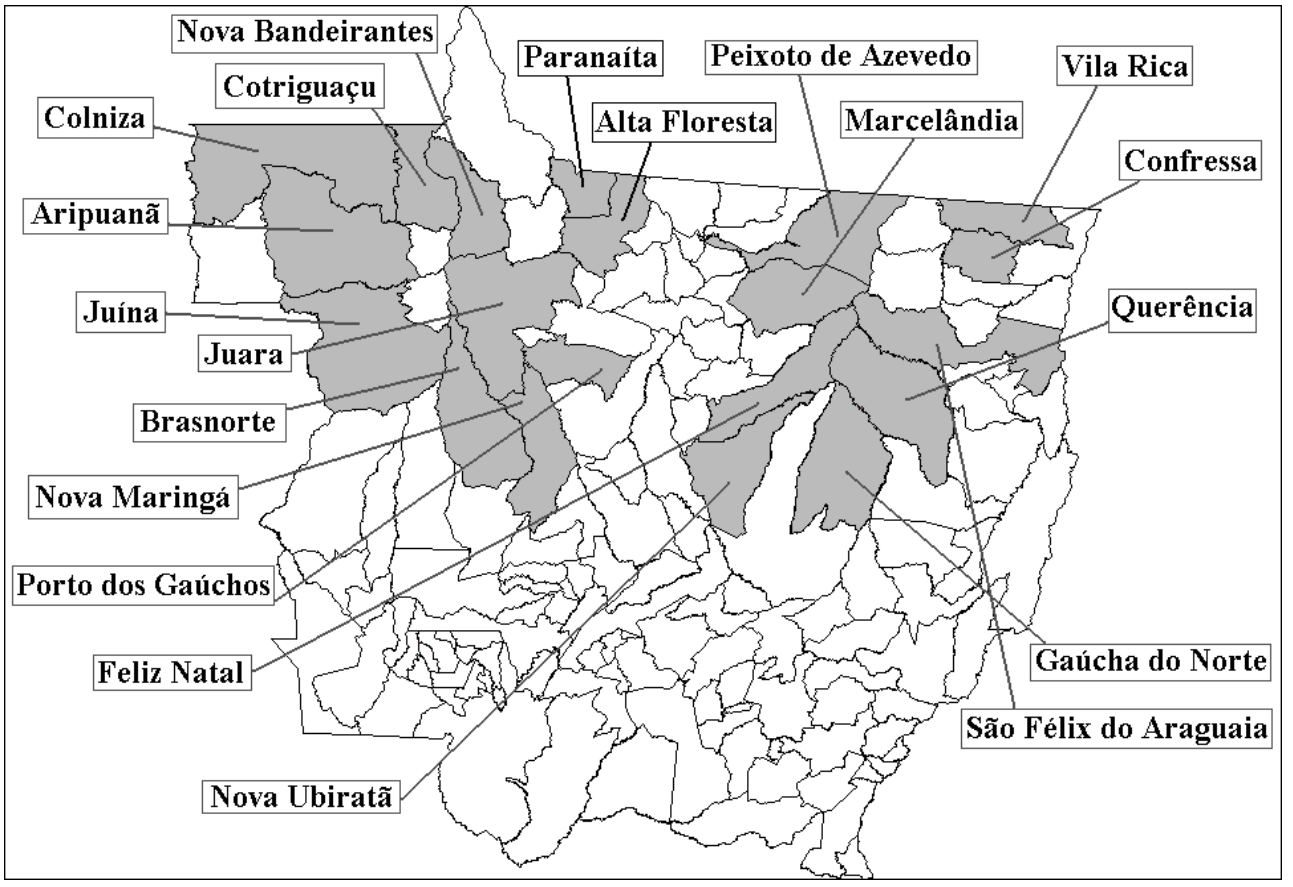

Fonte: Elaboração própria.

A Figura 1 contém os municípios que mais foram desmatados em Mato Grosso desde a década de 1970, ou seja, a lista elaborada pelo governo federal se utiliza de um conceito de estoque ao mensurar a destruição da floresta. Por sua vez, este artigo se propõe a verificar tal processo por meio de um conceito de fluxo, utilizando-se de dados recentes.

Pretende-se mostrar que o conceito de estoque adotado pelo governo federal deveria ser avaliado conjuntamente com os principais municípios responsáveis pelo desmatamento recente no estado de Mato Grosso. Na verdade, como o desmatamento é um fenômeno que independe do zoneamento geográfico de uma unidade espacial, deve ser avaliado através de um conceito de fluxo, incorporando o impacto da degradação de um dado município sobre seu vizinho. Ao se utilizar o ferramental da Aede e da econometria espacial, será possível verificar que o desmatamento atual segue uma dinâmica diferente daquela baseada no conceito de desmatamento acumulado, utilizado pelo governo federal.

\subsection{Análise Exploratória de Dados Espaciais (Aede)}

Conforme destacam Perobelli et al. (2007), a análise exploratória de dados espaciais está baseada em aspectos espaciais da base de dados, tratando diretamente de dependência espacial (isto é, associação espacial) e heterogeneidade 
espacial. Em suma, a finalidade da Aede é caracterizar a distribuição espacial, os padrões de associação espacial (clusters espaciais), verificar a ocorrência de diferentes regimes espaciais ou outras formas de instabilidade espacial (não estacionariedade) e identificar observações atípicas (outliers).

Para que a Aede seja implementada de maneira eficiente, é necessária a utilização de variáveis intensivas ou espacialmente densas, já que variáveis absolutas podem induzir a enganos na análise. A utilização do total de observações em números absolutos de um fenômeno não é aconselhável, tendo em vista que esses atributos podem estar correlacionados com variáveis de escala, o que geraria correlações espaciais espúrias. Nesse sentido, a divisão da variável de interesse por algum indicador de intensidade, como o número de habitantes ou o tamanho da área da região, por exemplo, soluciona esse problema (ANSELIN, 2005).

De acordo com Gonçalves (2005, p. 411), “[...] métodos convencionais, como regressões múltiplas e inspeção visual de mapas, não são formas mais adequadas de lidar com dados georreferenciados, pois não são confiáveis para detectar agrupamentos e padrões espaciais significativos".

A Aede é o método mais indicado para se obter medidas de autocorrelação espacial global e local, observando a influência dos efeitos espaciais por intermédio de instrumentos quantitativos, e não pelo "olho humano" (ANSELIN, 1995).

\subsubsection{Autocorrelação Espacial Global}

De acordo com Anselin (1988), um coeficiente de autocorrelação descreve um conjunto de dados que está ordenado em uma determinada frequência. Assim, um coeficiente de autocorrelação espacial descreve um conjunto de dados que está ordenado em uma sequência espacial.

Uma forma de calcular a autocorrelação espacial global é por meio do I de Moran. Essa é uma estatística que fornece de maneira formal o grau de associação linear entre os vetores de valores observados em um tempo $t\left(z_{t}\right)$ e a média ponderada dos valores dos seus vizinhos, ou as defasagens espaciais $\left(W z_{t}\right)$, como são mais conhecidos na literatura. Valores do I de Moran maiores ou menores do que o valor esperado $E(I)=-1 /(n-1)$ revelam autocorrelação espacial positiva ou negativa, respectivamente (PEROBELLI et al., 2007).

Os valores dessa estatística variam entre -1 e +1 , em que -1 representa um coeficiente de correlação linear perfeitamente negativa e +1 representa um coeficiente de correlação linear perfeitamente positiva (ANSELIN, 1995). Conforme Perobelli, Ferreira e Faria (2006), essa estatística pode ser representada através da seguinte notação matricial:

$$
I_{t}=\left(\frac{n}{S_{o}}\right)\left(\frac{z_{t}^{\prime} W z_{t}}{z_{t}^{\prime} z_{t}}\right) t=1, \ldots n
$$


Nessa equação, $z_{t}$ é o vetor de $n$ observações para o ano $t$ na forma de desvio em relação à média. W é a matriz de pesos espaciais que pode ser definida como uma matriz quadrada em que cada célula $w_{i j}$ indica relação existente entre as regiões $i$ e j em um sistema de $n$ regiões. A célula $w_{i j}$ é nula no caso das regiões não serem vizinhas, caso contrário o valor passa a ser 1. $S_{o}$ é igual a $\sum \sum w_{i j}$, significando que todos os elementos da matriz de pesos espaciais $W$ devem ser somados.

A matriz de pesos espaciais quando é normalizada na linha, isto é, quando a soma dos elementos da linha é igual a 1, fornece a expressão 2 da seguinte forma:

$$
I_{t}=\left(\frac{z_{t}^{\prime} W z_{t}}{z_{t}^{\prime} z_{t}}\right) t=1, \ldots n
$$

A literatura registra diversos modos de construir a matriz de pesos espaciais, entretanto, o critério utilizado neste trabalho baseia-se em uma matriz de $k$-vizinhos mais próximos. A ideia básica é que duas regiões próximas geograficamente têm maior interação espacial. Nesse aspecto, a matriz de $k$-vizinhos trata-se de uma matriz binária cuja convenção de vizinhança está formulada na distância geográfica (medida em quilômetros ou milhas, por exemplo). Formalmente, conforme Almeida, Perobelli e Ferreira (2008), tem-se:

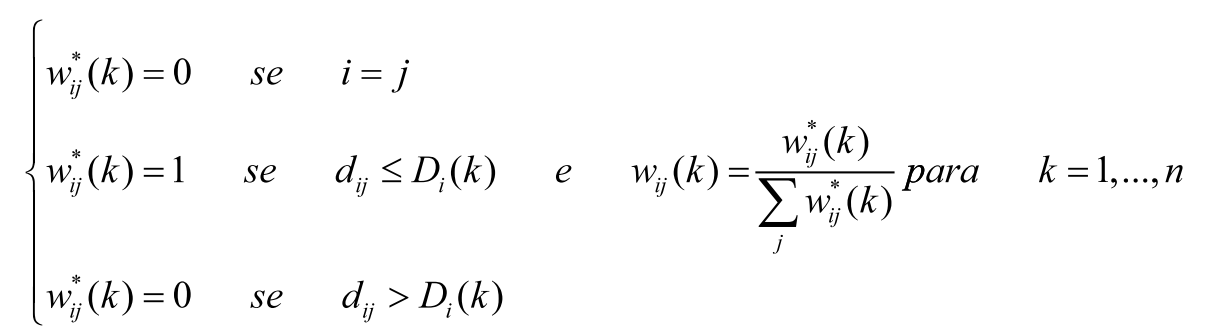

na qual $d_{i j}$ é a distância, medida pelo grande círculo, entre os centros das regiões $i$ e j, a fim de que a região $i$ tenha $k$-vizinhos; $D_{i}(k)$ denota um valor crítico que define o valor de corte para cada região, isto é, a distância máxima para considerar regiões vizinhas à região $i$, em que regiões acima desse ponto não serão consideradas vizinhas da região em questão; $W_{i j}$ representam os pesos espaciais, ou a influência da região $j$ sobre a região $i$, e $k$ representa o número de vizinhos adotados para a matriz utilizada.

Uma questão muito debatida na literatura é como se definir o número de k-vizinhos a ser considerado em um determinado estudo (na verdade não existe consenso). Com o intuito de tornar menos arbitrária essa definição, será adotado o critério proposto por Baumont (2004), que consiste em três passos:

a) processar o modelo econométrico proposto por mínimos quadrados ordinários (MQO); 
b) testar os resíduos para a autocorrelação espacial por intermédio do valor da estatística $I$ de Moran, usando $L$ matrizes de $k$-vizinhos mais próximos (variando $L$ de $k=1$ a $k=20$ );

c) definir $k$ que tenha gerado o maior valor do I de Moran, significativo estatisticamente.

Anselin (1995) considera que o I de Moran, por ser uma medida de associação espacial global, não é capaz de revelar padrões de associação espacial local. Dessa forma, a autocorrelação espacial local deve ser mensurada de outra forma.

\subsubsection{Autocorrelação Espacial Local}

O objetivo da autocorrelação espacial local é captar padrões de associação local (clusters ou outliers espaciais), que são geralmente ocultados pelas estatísticas de autocorrelação espacial global. A autocorrelação espacial local pode ser calculada pela estatística $I_{i}$ de Moran local, também conhecida como indicadores locais de associação espacial (Lisa). ${ }^{3}$

Conforme enfatiza Anselin (1995), os indicadores Lisa devem satisfazer dois critérios: a) possuir, para cada observação, uma indicação de clusters espaciais significantes de valores similares ao redor de cada observação, e b) o somatório dos indicadores Lisa, em todas as regiões, deve ser proporcional ao indicador de autocorrelação espacial global. Dessa maneira, o coeficiente $I_{i}$ de Moran local pode ser expresso como:

$$
I_{i}=\frac{\left(y_{i}-\bar{y}\right) \sum_{j} w_{j}\left(y_{j}-\bar{y}\right)}{\sum_{i}\left(y_{i}-\bar{y}\right)^{2} / n}
$$

em que $n$ é o número de regiões; $y_{i}$ é a variável de interesse; $\bar{y}$ é a média dessa variável; $y_{j}$ é a variável de interesse nas regiões vizinhas a $i$; e $w_{i j}$ é o elemento da matriz de pesos espaciais.

A interpretação para essa estatística é dada por quatro tipos de padrões espaciais:

a) o padrão alto-alto (AA) indica regiões com elevados valores para a variável de interesse, sendo vizinhas de regiões com elevados valores para a mesma;

b) o padrão baixo-baixo (BB) revela localidades com reduzidos valores para a variável em análise, sendo circundadas por localidades com baixos valores para a mesma;

No acrônimo, em inglês, Local indicators of spatial association. 
c) o padrão baixo-alto (BA) mostra localidades com baixos valores para a variável investigada, que são vizinhas de regiões com altos valores para a mesma;

d) por fim, o padrão alto-baixo (AB) caracteriza regiões com altos valores para a variável em estudo, que são ladeadas por outras com baixos valores para a mesma.

No entanto, os indicadores Lisa não conseguem mostrar formalmente o processo de convergência ao longo do tempo e do espaço. Para tanto, utilizam-se os modelos econométricos de convergência espacial.

\subsection{Modelos de Convergência Espacial}

Ao se definir um modelo que possa captar de maneira adequada, por exemplo, questões inerentes a efeitos de transbordamento entre diferentes localidades em estudo, os efeitos espaciais devem ser explicitamente considerados em sua forma funcional. Modelos tradicionais de regressão linear não levam em conta os efeitos espaciais de autocorrelação e heterogeneidade espacial. Desse modo, a estimação de modelos por MQO forneceria estimativas inconsistentes e/ou ineficientes (ANSELIN, 1988; ANSELIN, 1995; ANSELIN; BERA, 1998).

Autores como Florax, Folmer e Rey (2003) e Anselin (2005) sugerem o seguinte procedimento para a especificação de um modelo que leve em conta a presença de autocorrelação espacial:

a) estimar o modelo clássico de regressão linear por MQO;

b) testar a hipótese de ausência de autocorrelação espacial devido a uma defasagem ou a um erro através do multiplicador de Lagrange para a defasagem espacial $\left(M L_{\rho}\right)$ e o multiplicador de Lagrange para o erro espacial $\left(M L_{\lambda}\right)$;

c) caso ambos os testes sejam não significativos, deve-se utilizar o modelo clássico; caso contrário, segue-se o próximo passo;

d) se ambos os testes forem significativos, deve-se verificar as versões robustas de ambos, ou seja, o multiplicador de Lagrange robusto para a defasagem espacial $\left(M L R_{\rho}\right)$ e o multiplicador de Lagrange robusto para o erro espacial $\left(M L R_{\lambda}\right)$. Caso $M L R_{\rho}>M L R_{\lambda}$, identifica-se o modelo de defasagem espacial como o mais apropriado. Caso contrário, se $M L R_{\rho}<M L R_{\lambda}$, adota-se o modelo de erro espacial.

A estimação do modelo de $\beta$ convergência absoluta por $\mathrm{MQO}$ busca somente identificar qual a melhor maneira de se estimar a equação abaixo:

$$
1 n\left(\operatorname{Desm}_{t+n} / \operatorname{Desm}_{t}\right)=\alpha+\beta 1 n\left(\operatorname{Desm}_{t}\right)+\mu_{i}
$$


em que $1 n\left(\operatorname{Desm}_{t+n} / \operatorname{Desm}_{t}\right)$ é o logaritmo natural da razão entre a taxa de desmatamento entre o período final $t+n$ e o período inicial $t$ da análise; $\beta 1 n\left(\operatorname{Desm}_{t}\right)$ é o logaritmo natural do desmatamento no período inicial; e $u_{i}$ é o termo de erro bem comportado com média zero e variância constante.

\subsubsection{Modelo de Erro Espacial}

A primeira modificação que a equação 6 pode sofrer refere-se ao seu termo de erro, $u_{i}$, que pode seguir um processo autorregressivo, como mostrado nas equações 7 e 8 :

$$
\begin{gathered}
u_{i}=\lambda W u_{i}+\varepsilon_{i} \\
u_{i}=(I-\lambda W)^{-1} \varepsilon_{i}
\end{gathered}
$$

em que $\lambda$ representa o coeficiente escalar do erro espacial, e o termo de erro $\varepsilon_{i}$ possui distribuição normal com média zero e variância constante.

A utilização de $\mathrm{MQO}$ na presença de erros não esféricos geraria estimativas ineficientes, apesar de justas. Desse modo, a dependência espacial pode ser decorrente de efeitos não modelados que não foram aleatoriamente distribuídos através do espaço. A solução para tal problema repousa na estimação do modelo de erro espacial pelo método da máxima verossimilhança (MV) ou pelo método generalizado dos momentos (GM) de Kelejian e Prucha (1999).

Ao se substituir o termo de erro $u_{i}$ da equação $8 \mathrm{em} 6$, tem-se a forma convencional do modelo de convergência do erro espacial:

$$
\ln \left(\operatorname{Desm}_{t+n} / \operatorname{Desm}_{t}\right)=\alpha+\beta 1 n\left(\operatorname{Desm}_{t}\right)+(I-\lambda W)^{-1} \varepsilon_{i}
$$

Segundo Rey e Montoury (1999), quando $\lambda$ assume valor nulo não há autocorrelação espacial do erro. Contudo, quando $\lambda \neq 0$, um choque ocorrido em uma unidade geográfica se espalha não somente para seus vizinhos mais próximos, mas para todas as outras unidades.

\subsubsection{Modelo de Defasagem Espacial}

Esse modelo sugere que a autocorrelação espacial é fruto da interação atual entre as regiões. Nessa nova equação de $\beta$ convergência, é introduzida como variável independente a defasagem espacial da variável dependente. A equação 10 ilustra esse modelo: 


$$
1 n\left(\operatorname{Desm}_{t+n} / \operatorname{Desm}_{t}\right)=\alpha+\beta 1 n\left(\operatorname{Desm}_{t}\right)+\rho W 1 n\left(\operatorname{Desm}_{t+n} / \operatorname{Desm}_{t}\right)+\varepsilon_{i}
$$

na qual $\rho$ é o coeficiente da defasagem espacial, isto é, um escalar que, caso $\rho>$ $0(\rho<0)$, indica ocorrência de autocorrelação espacial positiva (negativa). Já o novo elemento da forma funcional $W 1 n\left(\operatorname{Desm}_{t+n} /\right.$ Desm $\left._{t}\right)$ é uma média dos valores da variável de interesse nas regiões vizinhas.

De acordo com Anselin (1988), ao não se considerar explicitamente a defasagem espacial nesse modelo, ocorreria um problema da mesma magnitude da omissão de variável relevante, isto é, os coeficientes estimados por MQO das variáveis explicativas seriam tendenciosos. Para se evitar tal problema, métodos de estimação alternativos, como o uso de variáveis instrumentais (VI) ou o método $\mathrm{MV}$, são recomendados.

\section{Resultados}

Inicialmente, adotou-se o procedimento de Baumont (2004) na escolha da matriz de pesos espaciais. Por esse critério, deve-se selecionar a matriz de $k$-vizinhos que apresente o maior valor para a estatística I de Moran global, com $k$ variando entre 1 e 20. Seguindo esse procedimento, estimou-se o I de Moran global para a taxa de desmatamento de Mato Grosso durante o período de 2000 a 2008, conforme a Tabela 1 . 
Tabela 1 - Estatística I de Moran global para a taxa de desmatamento no estado de Mato Grosso durante o período 2000-2008

\begin{tabular}{|c|c|c|c|c|c|}
\hline Matriz & I de Moran & Média & $\begin{array}{l}\text { Desvio } \\
\text { padrão }\end{array}$ & z - valor & $p$ - valor \\
\hline $\mathrm{k}=1$ & 0,5042 & $-0,007$ & 0,1053 & 4,8561 & 0,0000 \\
\hline $\mathrm{k}=2$ & 0,5072 & $-0,007$ & 0,0762 & 6,7530 & 0,0000 \\
\hline $\mathrm{k}=3$ & 0,5476 & $-0,007$ & 0,0621 & 8,9352 & 0,0000 \\
\hline $\mathrm{k}=4$ & 0,5551 & $-0,007$ & 0,0556 & 10,1140 & 0,0000 \\
\hline $\mathrm{k}=5$ & 0,5317 & $-0,007$ & 0,0497 & 10,8506 & 0,0000 \\
\hline $\mathrm{k}=6$ & 0,5288 & $-0,007$ & 0,0452 & 11,8577 & 0,0000 \\
\hline $\mathrm{k}=7$ & 0,5111 & $-0,007$ & 0,0416 & 12,4560 & 0,0000 \\
\hline $\mathrm{k}=8$ & 0,4889 & $-0,007$ & 0,0389 & 12,7420 & 0,0000 \\
\hline $\mathrm{k}=9$ & 0,4766 & $-0,007$ & 0,0369 & 13,1083 & 0,0000 \\
\hline $\mathrm{k}=10$ & 0,4603 & $-0,007$ & 0,0349 & 13,3725 & 0,0000 \\
\hline $\mathrm{k}=11$ & 0,4496 & $-0,007$ & 0,0333 & 13,7315 & 0,0000 \\
\hline $\mathrm{k}=12$ & 0,4411 & $-0,007$ & 0,0319 & 14,0259 & 0,0000 \\
\hline$k=13$ & 0,4278 & $-0,007$ & 0,0305 & 14,2508 & 0,0000 \\
\hline $\mathrm{k}=14$ & 0,4111 & $-0,007$ & 0,0292 & 14,3143 & 0,0000 \\
\hline $\mathrm{k}=15$ & 0,4060 & $-0,007$ & 0,0284 & 14,5649 & 0,0000 \\
\hline $\mathrm{k}=16$ & 0,3992 & $-0,007$ & 0,0277 & 14,8555 & 0,0000 \\
\hline $\mathrm{k}=17$ & 0,3905 & $-0,007$ & 0,0264 & 15,0556 & 0,0000 \\
\hline $\mathrm{k}=18$ & 0,3838 & $-0,007$ & 0,0256 & 15,2938 & 0,0000 \\
\hline$k=19$ & 0,3852 & $-0,007$ & 0,0246 & 15,9466 & 0,0000 \\
\hline $\mathrm{k}=20$ & 0,3778 & $-0,007$ & 0,0239 & 16,0920 & 0,0000 \\
\hline
\end{tabular}

Fonte: Elaboração própria a partir do programa SpaceStat e de dados do Brasil (2009a).

Essa tabela mostra que cada uma das 20 matrizes elaboradas possui um I de Moran global positivo e significativo, indicando que existe autocorrelação espacial positiva. Esta pode ser compreendida como um tipo de autocorrelação que revela municípios com elevadas taxas de desmatamento, possuindo como vizinhos municípios com elevados valores para essa mesma variável ou, de forma oposta, municípios com baixas taxas de desmatamento como vizinhos de municípios com reduzidos valores para essa taxa.

Segundo o procedimento de Baumont (2004), a matriz $k=4$ apresenta o maior valor para a estatística I de Moran global $(0,5551)$. Nesse aspecto, toma-se essa matriz como a que melhor representa o processo de autocorrelação espacial do desmatamento entre os municípios mato-grossenses, isto é, o desmatamento não segue um processo aleatório nessas localidades. Apesar de todas as matrizes de pesos espaciais revelarem valores positivos e significativos para o I de Moran 
global, escolhe-se a matriz $k=4$ por possuir maior força no processo de autocorrelação espacial.

Contudo, o I de Moran global fornece apenas uma tendência geral de ordenação dos dados espaciais, podendo esconder padrões locais significativos destoantes da média. Para tanto, existem os indicadores Lisa, que, através do calculo do I de Moran local, conseguem exprimir resultados locais relevantes com o auxílio do mapa de clusters. A Figura 2 mostra o mapa de clusters para o desmatamento nos municípios de Mato Grosso, durante o período 2000-2008, com um nível de significância de $5 \%$.

Figura 2 - Mapa de clusters para a taxa de desmatamento em Mato Grosso no período 2000-2008

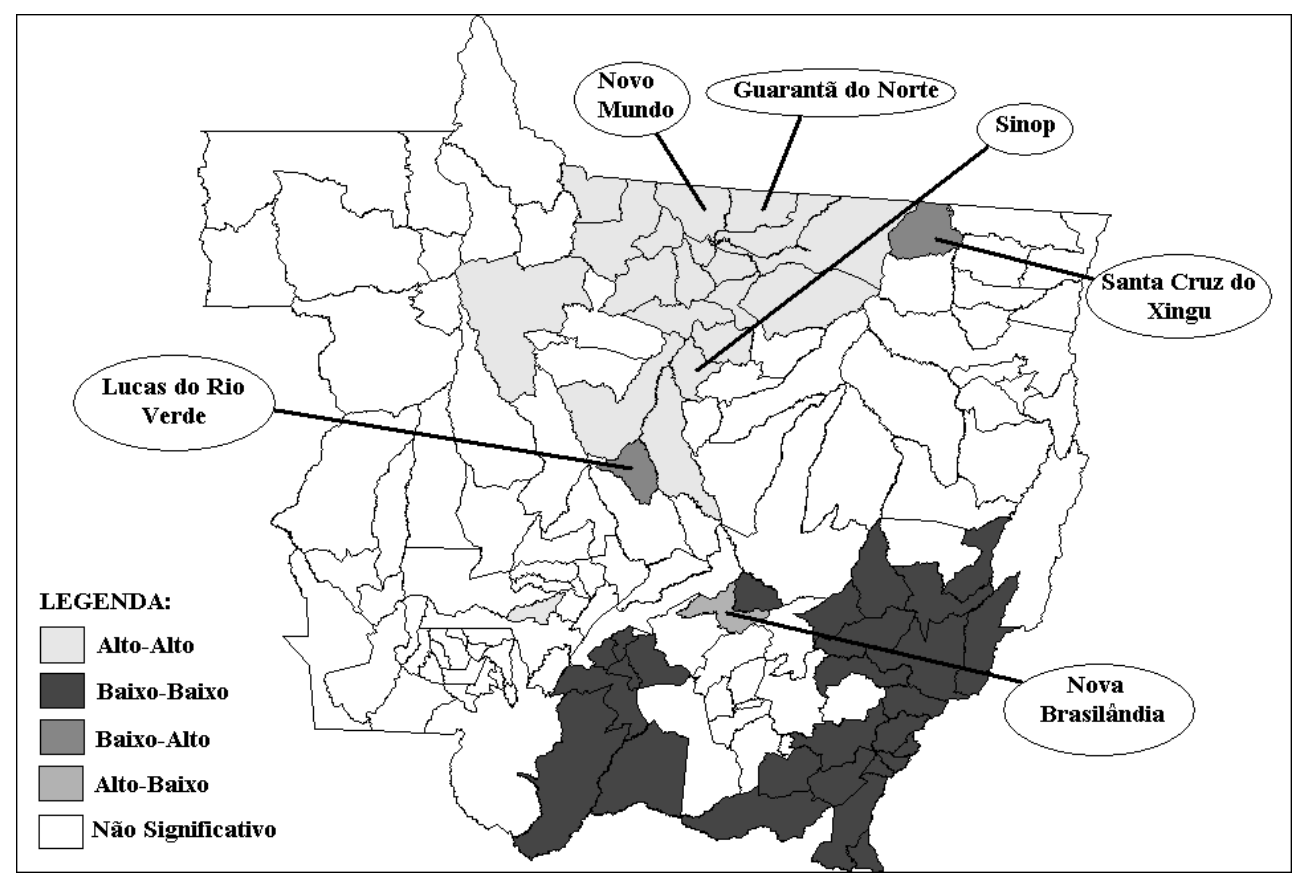

Fonte: Elaboração própria a partir do programa Geoda e de dados do Brasil (2009a).

Com base no mapa de clusters da Figura 2, é possível verificar que no período 2000-2008 encontram-se os quatro tipos de associação espacial possíveis, isto é, os padrões $\mathrm{AA}, \mathrm{BB}, \mathrm{BA}$ e $\mathrm{AB}$. No entanto, é nítido que existe um domínio da autocorrelação espacial positiva através dos padrões $\mathrm{AA}$ e $\mathrm{BB}$.

$\mathrm{O}$ padrão $\mathrm{AA}$ é formado por um grande cluster na região centro-norte de Mato Grosso, sendo composto pelos municípios de Alta Floresta, Carlinda, Claúdia, Colíder, Guarantã do Norte, Itaúba, Juara, Marcelândia, Matupá, Nova Canaã do Norte, Novo Mundo, Paranaíta, Peixoto de Azevedo, Sinop, Sorriso, Tapurah, Terra Nova do Norte, Nova Guarita e Nova Santa Helena, além do município de 
Nova Olímpia, na região central do estado, que não se caracteriza como cluster por estar isolado.

Esses resultados confirmam o estudo de Alencar et al. (2004), que enfatiza a região centro-norte (cortada pela BR-163) como a que apresenta as maiores taxas de desmatamento recente, com destaque para os municípios de Guarantã do Norte, Novo Mundo e Sinop.

Por outro lado, os municípios de Alta Floresta, Juara, Marcelândia, Paranaíta e Peixoto de Azevedo também estão presentes na lista do governo federal, constando como prioritários no combate ao desmatamento. Ou seja, esses municípios, além de possuírem elevado desmatamento acumulado, também fazem parte de um cluster de desmatamento recente, sinalizando que essas localidades tendem a dizimar rapidamente suas áreas de florestas.

Já o padrão BB apresenta dois grandes clusters: um localizado na região centro-sul, formada pelos municípios de Acorizal, Barão de Melgaço, Cuiabá, Jangada, Nossa Senhora do Livramento, Planalto da Serra, Poconé e Várzea Grande, e outro localizado na região sudeste, composto pelos municípios de Alto Araguaia, Alto Garças, Alto Taquari, Araguaiana, Araguainha, Barra do Garças, Campinápolis, General Carneiro, Guiritinga, Itiquira, Nova Xavantina, Novo São Joaquim, Pedra Preta, Pontal do Araguaia, Ponte Branca, Ribeirãozinho, Torixoréu, Nova Nazaré e Santo Antônio do Leste.

Por sua vez, o padrão $\mathrm{AB}$ encontra-se como um outlier na região central de Mato Grosso, sendo representado pelo município de Nova Brasilândia. E, por fim, o padrão BA também surge como outlier na região central do estado, com o município de Lucas do Rio Verde, e na região nordeste, com o município de Santa Cruz do Xingu.

A outra questão investigada neste artigo refere-se ao processo de convergência do desmatamento. Ao se processar a equação 6, que fornece a estimativa do coeficiente $\beta$, investiga-se a hipótese básica de homogeneização do desmatamento entre os municípios de Mato Grosso. Na prática, procura-se verificar se municípios com elevadas taxas de desmatamento no período inicial da análise tendem a reduzi-las mais rapidamente que municípios com baixas taxas de desmatamento, também no período inicial. A Tabela 2 reporta os resultados do modelo de $\beta$ convergência clássico, estimado por MQO, para o período 2000-2008, e para os subperíodos 2000-2003 e 2004-2008. 
Tabela 2 - Modelo tradicional para o desmatamento do estado de Mato Grosso durante os subperíodos 2000-2003, 2004-2008 e 2000-2008

\begin{tabular}{|c|c|c|c|}
\hline \multicolumn{4}{|c|}{ Modelos por MQO } \\
\hline Coeficiente & 2000-2003 & 2004-2008 & 2000-2008 \\
\hline \multirow[t]{2}{*}{$\alpha$} & 0,0014 & 0,0068 & 0,0141 \\
\hline & $(0,6375)$ & $(0,0000)$ & $(0,0002)$ \\
\hline \multirow[t]{2}{*}{$\beta$} & 0,1463 & 0,0223 & 0,1787 \\
\hline & $(0,0000)$ & $(0,0000)$ & $(0,0000)$ \\
\hline \multicolumn{4}{|l|}{ Estatística } \\
\hline $\mathrm{R}^{2}$ & 0,5614 & 0,1244 & 0,5435 \\
\hline $\mathrm{R}^{2}$ _ajustado & 0,5582 & 0,1180 & 0,5402 \\
\hline LIK & 333,035 & 420,832 & 300,183 \\
\hline AIC & $-662,071$ & $-837,663$ & $-596,367$ \\
\hline SC & $-656,202$ & $-831,794$ & $-590,498$ \\
\hline Multicolinearidade & 2,7071 & 2,7538 & 2,7071 \\
\hline Teste Jarque-Bera & $\begin{array}{l}29,1492 \\
(0,0000)\end{array}$ & $\begin{array}{l}13,4719 \\
(0,0000)\end{array}$ & $\begin{array}{c}2,1238 \\
(0,3458)\end{array}$ \\
\hline $\begin{array}{l}\text { Teste Koenker - Bas- } \\
\text { sett }\end{array}$ & $\begin{array}{l}24,8849 \\
(0,0000)\end{array}$ & $\begin{array}{c}6,5526 \\
(0,0105)\end{array}$ & $\begin{array}{l}48,1256 \\
(0,0000)\end{array}$ \\
\hline Estatística espaciaL & & Matriz $(k=4)$ & \\
\hline \multirow[t]{2}{*}{ I de Moran } & 0,1827 & 0,5330 & 0,4351 \\
\hline & $(0,0004)$ & $(0,0000)$ & $(0,0000)$ \\
\hline \multirow[t]{2}{*}{ ML - Erro } & 10,4117 & 88,6489 & 59,0624 \\
\hline & $(0,0013)$ & $(0,0000)$ & $(0,0000)$ \\
\hline \multirow[t]{2}{*}{ ML - Defasagem } & 6,0054 & 82,8488 & 31,7964 \\
\hline & $(0,0143)$ & $(0,0000)$ & $(0,0000)$ \\
\hline \multirow[t]{2}{*}{ MLR - Erro } & 4,4551 & 6,0435 & 27,2779 \\
\hline & $(0,0348)$ & $(0,0139)$ & $(0,0000)$ \\
\hline \multirow[t]{2}{*}{ MLR - Defasagem } & 0,0488 & 0,2434 & 0,0119 \\
\hline & $(0,8251)$ & $(0,6218)$ & $(0,9131)$ \\
\hline
\end{tabular}

Fonte: Elaboração própria a partir do programa SpaceStat e de dados do Brasil (2009a).

Nota: Probabilidades entre parênteses.

Como o coeficiente $\beta$ apresenta sinal positivo e revela-se estatisticamente significativo para o período completo da análise (2000-2008), assim como para os subperíodos (2000-2003) e (2004-2008), pode-se concluir que não há convergência, mas sim divergência, ou seja, existe um aumento das disparidades regionais em Mato Grosso, indicando que o processo de desmatamento tende a se desenvolver de maneira desigual entre os municípios mato-grossenses. 
Deve-se destacar que o processo de divergência vem perdendo força com o passar dos anos, pois o coeficiente $\beta$ que apresenta um valor de 0,1463 no período 2000-2003 reduz-se para 0,0223 no período 2004-2008. Caso essa tendência se mantenha ao longo dos próximos anos, o processo de divergência pode se tornar de convergência, mostrando que os municípios que mais desmatam estariam reduzindo suas taxas de desmatamento mais rapidamente que os municípios com baixas taxas para essa variável.

As estatísticas espaciais representadas pelos diferentes testes do multiplicador de Lagrange são as que indicam o modelo espacial a ser estimado. De acordo com a Tabela 2, tanto o multiplicador de Lagrange do erro espacial $\left(M L_{\lambda}\right)$ quanto o multiplicador de Lagrange da defasagem espacial $\left(M L_{\rho}\right)$ mostraram-se estatisticamente significativos para o período completo da análise, bem como para os subperíodos. Dessa forma, os multiplicadores de Lagrange do erro e da defasagem devem ser avaliados em suas versões robustas, conforme recomendam Florax, Folmer e Rey (2003) e Anselin (2005).

O multiplicador de Lagrange robusto para o erro espacial $\left(M R L_{\lambda}\right)$ mostrou-se estatisticamente significativo para todo o período 2000-2008 e para os subperíodos 2000-2003 e 2004-2008, não podendo se afirmar o mesmo a respeito do multiplicador de Lagrange robusto para a defasagem espacial $\left(M R L_{\rho}\right)$. Destarte, o modelo de erro espacial é tomado como o que melhor explica o processo de desmatamento entre os municípios de Mato Grosso.

No mais, é importante também sublinhar que o modelo estimado por MQO apresentou o problema da não normalidade nos resíduos para os subperíodos 2000-2003 e 2004-2008, como mostra o teste de Jarque-Bera. Por outro lado, o mesmo não pode ser dito do período 2000-2008, conforme o teste. Outra constatação é que todos os períodos de análise apresentam o problema da ausência de homocedasticidade, como indica o teste de Koenker-Bassett. Nesse aspecto, as especificações dos modelos de erro espacial foram modificadas para acomodar a heterocedasticidade na forma de grupos (groupwise heteroskedasticity), ${ }^{4}$ conforme recomendam autores como Perobelli, Ferreira e Faria (2006) e Almeida, Perobelli e Ferreira (2008).

Dessa maneira, todos os modelos de erro espacial foram estimados tanto pelo método $\mathrm{GM}$, quanto pelo método $\mathrm{MV}$, tendo em vista que são os mais indicados. A Tabela 3 reporta os resultados.

Foi utilizada como variável dummy a existência ou não de conselho municipal de meio ambiente nos municípios de Mato Grosso. Assim, municípios que possuem conselho municipal de meio ambiente receberam o valor unitário, ao passo que municípios sem o referido conselho foram classificados com o valor zero, conforme Barcellos e Carvalho (2009). 
Tabela 3 - Modelos de erro espacial para o desmatamento do estado de Mato Grosso durante os subperíodos 2000-2003, 2004-2008 e 2000-2008

\begin{tabular}{|c|c|c|c|c|c|c|}
\hline \multirow{3}{*}{ Coeficiente } & \multicolumn{2}{|c|}{$2000-2003$} & \multicolumn{2}{|c|}{ 2004-2008 } & \multicolumn{2}{|c|}{$2000-2008$} \\
\hline & Modelo 1 & Modelo 2 & Modelo 3 & Modelo 4 & Modelo 5 & Modelo 6 \\
\hline & MV & GM & MV & GM & MV & GM \\
\hline \multirow[t]{2}{*}{$\alpha$} & 0,0021 & 0,0021 & 0,0087 & 0,0085 & 0,0165 & 0,0164 \\
\hline & $(0,5615)$ & $(0,5612)$ & $(0,0002)$ & $(0,0001)$ & $(0,0012)$ & $(0,0012)$ \\
\hline \multirow[t]{2}{*}{$\beta$} & 0,1442 & 0,1440 & 0,0196 & 0,0200 & 0,1741 & 0,1742 \\
\hline & $(0,0000)$ & $(0,0000)$ & $(0,0004)$ & $(0,0003)$ & $(0,0000)$ & $(0,0000)$ \\
\hline \multirow[t]{2}{*}{$\lambda$} & 0,3116 & 0,3313 & 0,6445 & 0,6049 & 0,5276 & 0,5196 \\
\hline & $(0,0039)$ & $(0,0000)$ & $(0,0000)$ & $(0,0000)$ & $(0,0000)$ & $(0,0000)$ \\
\hline \multicolumn{7}{|l|}{ Estatística } \\
\hline $\mathrm{R}^{2}$ & 0,5454 & 0,5444 & 0,0965 & 0,1001 & 0,5158 & 0,5166 \\
\hline LIK & 339,002 & & 458,227 & & 323,137 & \\
\hline AIC & $-674,004$ & & $-912,454$ & & $-642,275$ & \\
\hline SC & $-668,135$ & & $-906,585$ & & $-636,406$ & \\
\hline Teste & \multicolumn{2}{|c|}{0,2062} & \multicolumn{2}{|c|}{0,0256} & \multicolumn{2}{|c|}{1,5381} \\
\hline \multicolumn{7}{|l|}{ Koenker- } \\
\hline Bassett & \multicolumn{2}{|c|}{$(0,6497)$} & \multicolumn{2}{|c|}{$(0,8729)$} & \multicolumn{2}{|c|}{$(0,2149)$} \\
\hline
\end{tabular}

Fonte: Elaboração própria a partir do programa SpaceStat e de dados de Brasil (2009a).

Nota: Probabilidades entre parênteses.

Como pode-se observar, o coeficiente $\beta$ obtido para os seis modelos foi novamente positivo e estatisticamente significativo, reforçando os resultados obtidos pelo modelo de $\mathrm{MQO}$, ou seja, não existe um processo de convergência do desmatamento entre os municípios mato-grossenses, mas sim um processo de divergência espacial. Outra constatação é que, independentemente do período investigado, a magnitude do coeficiente $\beta$ pouco se altera, seja estimado por MQO, MV ou GM.

Todos os seis modelos de erro espacial apresentaram coeficientes $\lambda$ altamente significativos do ponto de vista estatístico, revelando que a dependência espacial no processo de desmatamento entre os municípios mato-grossenses se encontra no termo de erro. Por sua vez, ao se acomodar a heterocedasticidade na forma de grupos, a hipótese nula de que os erros possuem variância constante, homocedasticidade, não pode ser rejeitada em um nível de $5 \%$ de significância, conforme indica o teste de Koenker-Bassett.

Ao se elaborar diferentes modelos de erro espacial para os distintos períodos investigados, verifica-se que a presença explícita de um componente espacial na forma de erro ajuda a explicar o processo de divergência do desmatamento entre os municípios mato-grossenses, corroborando a importância da metodologia empregada. 


\section{Considerações Finais}

O governo federal brasileiro considera o estado de Mato Grosso prioritário no combate ao desmatamento, principalmente por apresentar 20 dos 43 municípios de toda a Amazônia Legal com os maiores valores históricos acumulados para essa variável.

Nesse sentido, este trabalho contribui com importantes evidências sobre a autocorrelação espacial do desmatamento em Mato Grosso. Conforme pôde ser constatado pelo ferramental da Aede, independentemente do fator responsável pelo desmatamento nesse estado, seja a pecuária, a sojicultura, a exploração da madeira, ou qualquer outro, verificou-se a natureza multidirecional desse processo no espaço.

Assim, para verificar a relevância do caso mato-grossense, foram elaboradas as estatísticas de Aede para o período 2000-2008 e para os subperíodos 2000-2003 e 2004-2008. Adotou-se essa metodologia por ser a mais apropriada para dados georreferenciados, pois engloba o conceito de fluxo (períodos de tempo recentes e definidos), bem como o processo de dependência espacial que um determinado município exerce sobre o outro.

De início, foi avaliada a autocorrelação espacial por intermédio do I de Moran global, que confirmou a existência de dependência espacial entre os municípios de Mato Grosso para o processo de desmatamento. Em seguida, os indicadores Lisa refinaram esses resultados, mostrando quais são os municípios mato-grossenses que apresentaram algum tipo de padrão espacial para o desmatamento.

Tomando como base o período completo de estudo, de 2000 a 2008, chegou-se à conclusão que o padrão AA é formado por um grande cluster de desmatamento na região centro-norte de Mato Grosso, sendo composto pelos municípios de Alta Floresta, Carlinda, Claúdia, Colíder, Guarantã do Norte, Itaúba, Juara, Marcelândia, Matupá, Nova Canaã do Norte, Novo Mundo, Paranaíta, Peixoto de Azevedo, Sinop, Sorriso, Tapurah, Terra Nova do Norte, Nova Guarita e Nova Santa Helena. Pela metodologia empregada, todos esses municípios deveriam fazer parte de uma lista prioritária para o combate ao desmatamento no estado, tendo em vista a relevância dessas localidades no processo de desmatamento recente. Em síntese, o conceito de estoque priorizado pelo governo federal para determinar o desmatamento no estado revela-se insuficiente para compreender a dinâmica atual desse processo.

Por sua vez, as análises de convergência para todos os períodos investigados em Mato Grosso apresentaram coeficientes $\beta$ positivos e significativos, sugerindo que está ocorrendo divergência e não convergência do desmatamento. Todavia, verificou-se que as disparidades municipais estão crescendo a taxas decrescentes, 
sugerindo que o processo de divergência pode se tornar de convergência com o passar dos anos.

Nesse sentido, constatou-se que os modelos de erro espacial foram os mais indicados para todos os períodos analisados, conforme os testes de multiplicador de Lagrange. Ou seja, ao se regredir as equações de erro espacial para o desmatamento, todos os coeficientes $\lambda$ mostraram-se altamente significativos, independentemente do método de estimação utilizado (MV ou VI), confirmando que a dependência espacial do desmatamento entre os municípios mato-grossenses está no termo de erro.

Sendo assim, a sugestão para a elaboração de uma política pública de combate ao desmatamento em Mato Grosso refere-se à criação de uma lista com os municípios mato-grossenses que mais vêm sofrendo com o desmatamento recente, conforme se constatou no estudo. O mapeamento das cidades com os maiores índices de desmatamento seria importante para auxiliar no planejamento de autoridades em âmbito federal, estadual e municipal, inclusive contribuindo para que a divergência do desmatamento em Mato Grosso se direcione para um processo de convergência.

Como sugestão de melhoria em trabalhos futuros, pode-se citar a importância de estimativas que incluam demais variáveis explicativas nas regressões de convergência para o desmatamento em Mato Grosso, também conhecido como modelos de convergência condicional ou $\delta$ convergência. Algumas importantes variáveis a serem investigadas seriam: as plantações de soja, a extração madeireira, a pecuária, as plantações de cana-de-açúcar, a malha rodoviária estadual para o escoamento da produção e a presença de assentamentos rurais, as quais pressionariam a demanda por terras com cobertura florestal. Outra linha interessante para trabalhos futuros refere-se à estimação de modelos de convergência para o desmatamento através do método das regressões geograficamente ponderadas (RGP), uma das abordagens que mais vem sendo utilizada em econometria espacial.

\section{Referências}

ALENCAR, A. et al. Desmatamento na Amazônia: indo além da emergência crônica. Belém: Instituto de Pesquisa Ambiental da Amazônia, 2004.

ALMEIDA, E. S.; PEROBELLI, F. S.; FERREIRA, P. G. C. Existe convergência espacial da produtividade agrícola no Brasil? Revista de Economia e Sociologia Rural, v. 46, n. 1, p. 31-52, jan./mar. 2008.

ANSELIN, L. Exploring spatial data with GeoDa: a workbook. Urbana-Champaign: University of Illinois, 2005.

Local indicators of spatial association - LISA. Geographical Analysis, v. 27 n. 2, p. 93-115, Apr. 1995. 
Spatial econometrics: methods and models. Boston: Kluwer Academic, 1988.

ANSELIN, L.; BERA, A. Spatial dependence in linear regression models with an introduction to spatial econometrics. In: ULLAH, A.; GILES, D. E. (Ed.). Handbook of applied economic statistics, Marcel Dekker, NY, p. 237-289, 1998.

ANSELIN, L.; SYABRI, I.; SMIRNOV, O. Visualizing multivariate spatial correlation with $d y$ namically linked Windows. Mimeo: Universityof Illinois, 2003.

ARRAES, R. A.; DINIZ, M. B.; DINIZ, M. J. T. Curva ambiental de Kuznets e desenvolvimento econômico sustentável. Revista de Economia e Sociologia Rural, v. 44, n. 3, p. 525-547, jul./ set. 2006.

BARCELLOS, F. C.; CARVALHO, P. G. M. Municípios com instrumentos de gestão ambiental. In: VIII ENCONTRO DA SOCIEDADE BRASILEIRA DE ECONOMIA ECOLÓGICA, 8., 2009, Cuiabá. Anais... Cuiabá: Anais do VIII Encontro da Sociedade Brasileira de Economia Ecológica, 2009. v. 1.

BARRO, R. J.; SALA-I-MARTIN, X. Convergence across states and regions. Economic Activity, n. 1, p. 107-182, 1991. (Brookings Papers).

BAUMOL, W. J. Productivity growth, convergence, and welfare: what the long run data show. American Economic Review, v. 76, n. 5, p. 1072-1085, 1986.

BAUMONT, C. Spatial effects in housing price models: do housing prices capitalize urban development policies in the agglomeration of Dijon (1999)? Pôle d'Economie et de Gestion: Université de Bourgogne, 2004.

BRASIL. Ministério da Ciência e Tecnologia. Projeto Prodes: monitoramento da floresta amazônica brasileira por satélite. Brasília, 2009a. Disponível em: < http://www.obt.inpe.br/ prodes/index.html >. Acesso em: 16 maio 2009.

. Ministério da Fazenda. Tesouro Nacional. Execução orçamentária dos estados. Brasília, 2009. Disponível em: http://www3.tesouro.gov.br/estados_municipios/transferencias constitucionais_novosite.asp.Acesso em: 4 set. 2009.

BROCK, W.; TAYLOR, M. The Green Solow model. Journal of Economic Growth, Springer, v. 15, n. 2, p. 127-153, June 2010.

CARVALHO, T. S.; ALMEIDA, E. S. A hipótese da curva de Kuznets ambiental global: uma perspectiva econométrico-espacial. In: CONGRESSO DA SOCIEDADE BRASILEIRA DE ECONOMIA, ADMINISTRAÇÃO E SOCIOLOGIA RURAL, 46., 2008, Rio Branco. Anais... Rio Branco: Sober, 2008.

DALL'ERBA, S. Productivity convergence and spatial dependence among Spanish regions. Illinois, 2003. (Working Paper Real/UIUC).

DE LONG, J. B. Productivity growth, convergence, and welfare: comment. American Economic Review, v. 78, n. 5, p. 1138-1154, Dec. 1988.

FEARNSIDE, P. M. Combate ao desmatamento na Amazônia brasileira. Cadernos da Biodiversidade, Curitiba, v. 2, n. 2, p. 35-39, 1999.

. Homem e ambiente na Amazônia. In: FEARNSIDE, P. M. (Org.). A floresta Amazônica nas mudanças globais. Manaus: INPA, 2003. p. 1-18.

FERREIRA, D. A. C. et al. Mato, grosso até quando? Ciência Hoje, v. 42, n. 248, p. 26-31, 2008. 
FLORAX, R. J. G. M.; FOLMER, H., REY, S. J. Specification searches in spatial econometrics: the relevance of Hendry's methodology. Regional Science and Urban Economics, v. 33, n. 5, p. 557-79, 2003.

FONSECA, L. N.; RIBEIRO, E. P. Preservação ambiental e crescimento econômico no Brasil. In: ENCONTRO DE ECONOMIA DA REGIÃO SUL, 7., 2005, Porto Alegre. Anais... Porto Alegre: Anpec Sul, 2005.

GEIST, H. J; LAMBIN, E. F. What drives tropical deforestation? Land - Use and Land - Cover Change (LUCC). International Human Dimensions Programme on Global Environmental Change (IHDP), Internacional Geosphere - Biosphere Programme (IGBP), LUCC Report Series $n^{\circ}$ 4. Louvain-la-Neuve, 2001.

GOMES, S. C.; BRAGA, M. J. Desenvolvimento econômico e desmatamento na Amazônia Legal: uma análise econométrica. In: CONGRESSO DA SOCIEDADE BRASILEIRA DE ECONOMIA, ADMINISTRAÇÃO E SOCIOLOGIA RURAL, 46, 2008, Rio Branco. Anais... Rio Branco: Sober, 2008.

GONÇALVES, E. Distribuição espacial da atividade inovadora brasileira: uma análise exploratória. Belo Horizonte: UFMG, 2005. (Texto para discussão Cedeplar n. 246).

GROSSMAN, G.; KRUEGER, A. Environmental impacts of a North American free trade agreement. Cambridge, USA: NBER, 1991. (NBER Working Paper n. 3914, Nov. 1991).

IGLIORI, D. Deforestation, growth and agglomeration effects: evidence from agriculture in the Brazilian Amazon. Cambridge, UK: University of Cambridge, 2008. (Discussion Paper Series $\left.n^{\circ} 28,2008\right)$.

INSTITUTO BRASILEIRO DE GEOGRAFIA E ESTATÍSTICA. Índice de preços ao produtor: indústria de transformação - outubro 2013. Disponível em: <http://www.sidra.ibge.gov.br/ bda >. Acesso em: 6 set. 2013.

INSTITUTO DE PESQUISAS ESPACIAIS. Disponível em: < http://www.obt.inpe.br/prodes/ index.php>. Acesso em: 16 maio 2009.

KELEJIAN, H. H.; PRUCHA, I. R. A generalized moments estimator for the autoregressive parameter in a spatial model. International Economic Review, v. 40, n. 2, 1999.

KUZNETS, S. Economic growth and income inequality. American Economic Review, Nashville, v. 45, n. 1, p. 1-28, Jan. 1955.

LOPES, J. L. Avaliação do processo de convergência da produtividade da terra na agricultura brasileira no período 1960 a 2001. 2004. 193 f. Tese (Doutorado em Economia). Universidade de São Paulo, Piracicaba, 2004.

LUCENA, A. F. P. Estimativa de uma curva de Kuznets ambiental aplicada ao uso de energia e suas implicações para as emissões de carbono no Brasil. 2005. 124 f. Dissertação (Mestrado em Planejamento Energético). Universidade Federal do Rio de Janeiro, Rio de Janeiro, 2005.

MADDISON, D. Environmental Kuznets curves: a spatial econometrics approach. Journal of Environmental and Management, London, v. 51, n. 2, p. 218-230, 2006.

MARGULIS, S. Causas do desmatamento da Amazônia brasileira. Brasília: Banco Mundial 2003.

MATO GROSSO (estado). Secretaria do Meio Ambiente. Plano de ação para prevenção e controle do desmatamento e queimadas do estado do Mato Grosso. Cuiabá: Sema, 2009. 
MICOL, L.; ANDRADE, J.; BÖRNER, J. Redução das emissões do desmatamento e da degradação (REDD): potencial de aplicação em Mato Grosso. Cuiabá: Instituto Centro de Vida, 2008.

ODLAND, J. Spatial autocorrelation. Londres: Sage Publications, 1988.

PEROBELLI, F. S. et al. Análise espacial da produtividade do setor agrícola brasileiro: 19912003. Nova Economia, Belo Horizonte, v. 17, n. 1, p. 65-95, jan./abr. 2007.

PEROBELLI, F. S.; FERREIRA, P. G.; FARIA, W. R. Análise de convergência no estado de Minas Gerais: 1975-2003. In: ENCONTRO REGIONAL DE ECONOMIA, 11., 2006, Fortaleza. Anais... Fortaleza: BNB, 2006.

QUAH, D. T. Regional convergence clusters across Europe. European Economic Review, v. 40, n. 3-5, p. 951-958, 1996.

REIS, E. J.; GUZMÁN, R. M. An econometric model of Amazon deforestation. Brasília: IPEA, 1992. (Texto para discussão Ipea n. 265).

REY, J. S.; MONTOURY, B. D. US regional income convergence: a spatial econometric perspective. Regional Studies, v. 33, n. 2, p. 143-156, 1999.

SANTOS, R. B. N. et al. Estimativa da curva de Kuznets ambiental para a Amazônia Legal. In: CONGRESSO DA SOCIEDADE BRASILEIRA DE ECONOMIA, ADMINISTRAÇÃO E SOCIOLOGIA RURAL, 46., 2008, Rio Branco. Anais... Rio Branco: Sober, 2008.

SHAFIK, N.; BANDYOPADHYAY, S. Economic growth and environmental quality: a time series and cross-country evidence. Washington: World Bank, 1992. (Policy Research Working Paper n. 904, June 1992).

STERN, D. I. Applying recent developments in time series econometrics to the spatial domain. Professional Geographer, Washington, v. 52, n. 1, p. 37-49, Feb. 2000.

. Progress on the environmental Kuznets curve? Environmental and Development Economics, Cambridge, v. 3, n. 2, p. 173-196, May, 1998.

TEIXEIRA, R. F. A. P. Amazônia Legal e o estado de Mato Grosso: dois ensaios sobre o processo de convergência espacial para o desmatamento. 2010. 142 f. Dissertação (Mestrado em Economia) - Universidade Estadual Paulista Júlio de Mesquita, Araraquara, 2010.

TEIXEIRA, R. F. A. P.; BERTELLA, M. A.; TOGEIRO, L. A. Curva de Kuznets ambiental para o estado de Mato Grosso. Análise Econômica, Porto Alegre, v. 30, n. 57, p. 313-337, mar. 2012.

Recebido em: 21/09/2010.

Aceito em: 18/06/2013. 